\title{
Effect of entrepreneurial self-efficacy and proactive personality on the entrepreneurial intention of post-migrant workers through attitude toward entrepreneurship
}

\author{
G. Rosalina \& A. Satrya \\ Faculty of Economy and Business, University Indonesia, Jakarta, Indonesia
}

\begin{abstract}
The purpose of this research is to examine the effects of entrepreneurial selfefficacy and proactive personalities on entrepreneurial intentions among migrant returnees through attitude toward entrepreneurship. This research employs a survey-based methodology and uses a 27item questionnaire with five-point Likert for a total sample of 195 migrant returnees. The research was conducted in the East Nusa Tenggara province, Indonesia. The hypotheses derived from the research model were assessed through structural equation modeling using Lisrel. The results show the indirect effect on the relationship between proactive personality and entrepreneurial intention through attitude toward entrepreneurship, while entrepreneurial self-efficacy was found to have a significant negative effect on entrepreneurial intention. By doing so, this research significantly contributes to the literature of entrepreneurship. The results also provide policy makers with important insights on developing entrepreneurial intentions on post-migrant workers and giving attention to key elements of the entrepreneurial process.
\end{abstract}

\section{INTRODUCTION}

Entrepreneurship is widely recognized as a determining factor that can improve social and economic development, both in developing and developed countries. Entrepreneurship plays an important role in creating new jobs, thus helping the government in dealing with unemployment and poverty problems (Asad, Ali, \& Islam, 2014). According to the data retrieved from the Ministry of Cooperatives and SMEs of The Republic of Indonesia in 2019, it is known that MSMEs contribute $60.34 \%$ to Indonesia's GDP. One of the groups in the society that have the potential to be developed into entrepreneurs is migrant workers, who have returned to their country after going abroad to have a job for a certain period of time. A study conducted by Demurger and Xu (2011) found that the migration experience allows them to bring back accumulated human, social, and financial capital that will enable them to set up their own businesses upon returning.

Given the increasing recognition of the role of entrepreneurship as an important driver for economic development and innovation, many studies have focused on developing models for understanding and predicting entrepreneurial intention as an important factor in shaping entrepreneurial behavior. From many studies conducted to identify factors that affect entrepreneurship, personal characteristics and basic psychological conditions are considered to be the most interesting factors that affect entrepreneurial intention (Khuong \& An, 2016). Entrepreneurial self-efficacy and proactive personality have emerged as the main psychological constructs in research on entrepreneurship because they can affect entrepreneurial motivation, intention, behavior, and performance (Miao, Qian, \& Ma, 2017). Therefore, the purpose of this research is to examine the influence of entrepreneurial self-efficacy and proactive personality on entrepreneurial intention on returned migrant workers mediated by attitude toward entrepreneurship. 


\section{LITERATURE REVIEW}

Entrepreneurship intention (EI) is a person's desire to consider entrepreneurship as a career choice, serving as the initial stage in the process of forming entrepreneurial behavior. Ajzen (2011) describes intention as an indication of a person's readiness to perform certain actions. Krueger et al. (2000) defines entrepreneurial intentions as individual beliefs in preparing and realizing entrepreneurial behavior or planned behavior to start a new business (Liu, Lin, Zhao, \& Zhao, 2019).

The term entrepreneurial self-efficacy (ESE) comes from the social learning theory developed by Bandura (1977). In this theory, self-efficacy is defined as an individual's belief in their capacity to take actions that can provide certain results, which reflects their belief in their ability to exercise control over motivation, behavior, and the social environment (Yueh, Wu, \& Chen, 2020). The definition of self-efficacy in this theory also explains the role of individual beliefs in their ability to create the environment and the expected results from their personal actions.

Some researchers agree that proactive personality (PP) is one of the strong predictors of entrepreneurial intentions. Bateman and Crant (1999) defines proactive behavior as taking initiative action to improve the current state and refuse to passively adapt to current conditions. A proactive attitude is also an important attribute of flexibility and adaptability to face an uncertain future, which is very much needed in the entrepreneurial process (Prabhu, McGuire, Drost \& Kwong, 2012).

Attitude toward entrepreneurship (ATE) refers to the degree to which a person gives an evaluation, either positively or negatively, about perception of developing an entrepreneurial career. Someone who has a positive assessment of entrepreneurial behavior tends to try to find and start a new business because they think it will bring benefits for them. Some researchers also support the role of attitude as a mediator between the personal characteristic and self-efficacy with behavioral intentions (Rosique-Blasco, Madrid-Guijarro, \& Lema, 2018). Therefore, the proposed hypotheses are as follows:

H1. PP has a significant positive effect on ATE.

H2. ESE has a significant positive effect on ATE.

H3. ATE has a significant positive effect on EI.

H4. PP has a significant positive effect on EI.

H5. ESE has a significant positive effect on EI.

H6. PP has a significant positive effect on EI through mediation of ATE.

H7. ESE has a significant positive effect on EI through mediation of ATE.

\section{RESEARCH METHOD}

\subsection{Types and data source}

This study used quantitative research. The data were collected from the returned migrant workers in Kupang City, East Nusa Tenggara province, Indonesia, with convenient sampling techniques. Participants were asked to complete a questionnaire consisting of 4 sections and 27 questions, covering general and variable questions including indicator questions for entrepreneurial intention, entrepreneurial self-efficacy, proactive personality, and attitude toward entrepreneurship.

\subsection{Measurement scales and data analysis}

This study used the established measures of constructs based on the earlier studies. In this study, the entrepreneurial self-efficacy was measured using questionnaire items from the research of Wilson, Kickul, and Marlino (2007), proactive personality variables were measured using questionnaire items from the research of Seibert, Krant, \& Kraimer (2001), attitude toward entrepreneurship was measured using questionnaire items from the research of Solesvik et al. (2012), and measurement of entrepreneurial intention variables were measured using questionnaire items from the research of Linan and Chen (2009). Demographic variables including age, gender, education, and marital status will be controlled in this study. The participants were asked whether they agreed or disagreed 
with a set of sentences across a 5 -point Likert scale, where $1=$ strongly disagree and $5=$ strongly agree. The data were analyzed using SPSS version 25 and Lisrel 8.54 by performing structural equation modeling (SEM).

\section{RESULTS AND DISCUSSION}

A total of 195 responses were obtained. Most of the respondents were female (74.4\%), married (61.54\%), had graduated from elementary schools (30.7\%), and in the age groups of $31-40(49.2 \%)$. Validity and reliability of each indicator used in the study were tested. Specifically, this study used standardized loading factor, composite reliability (CR), and average variance extracted (AVE) to assess the adequacy of outer-measurement models. The SEM results indicate that the questionnaire items used are valid and reliable because CR values are above 0.7 and SLF and AVE values are also above 0.5 (Hair et al., 2017).

Figure 1 shows the hypothesis testing results indicating that proactive personality (PP) was significantly and positively related to attitude toward entrepreneurship (ATE) ( $\mathrm{t}$-values $=10.57$, $\beta=.82$ ). Furthermore, ATE and entrepreneurial intention (EI) showed a positive and significant relationship (7.34, $\beta=0.83$ ), but there was no significant relationship between PP and EI (.04, $\beta=.01)$. From the analysis, ATE was known to have a full mediated effect in the relationship between PP and EI. From the result, it was known that entrepreneurial self-efficacy (ESE) and ATE did not have a significant and positive relationship ( $\mathrm{t}$-value $=-.42, \beta=.02$ ). ESE and EI were known to have a significant effect but in the opposite direction because the $t$ value obtained was negative ( $\mathrm{t}$-value $=-3.00, \beta=-.01$ ). This result is contrary to the initial hypothesis and several previous studies indicating that ESE has a significant positive effect on entrepreneurial intention. Attitudes toward entrepreneurship has no mediation effect in the relationship between entrepreneurial self-efficacy and entrepreneurial intention.

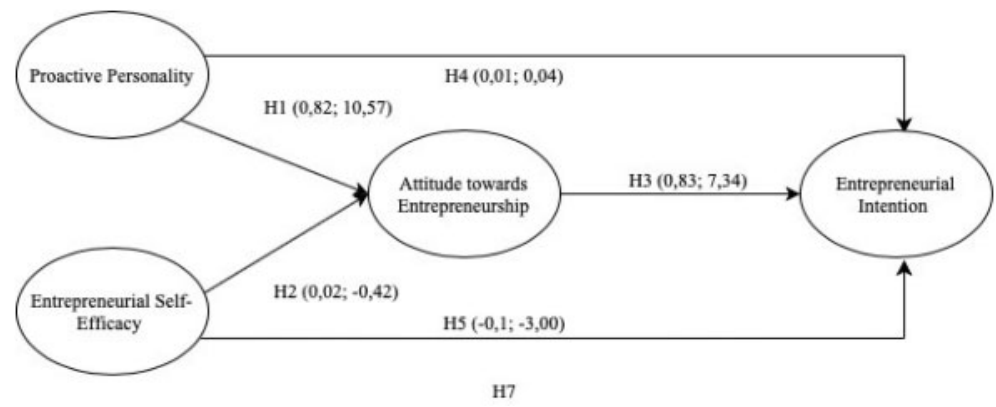

Figure 1. Test result.

This research provides valuable insights into the importance of personality traits in the determination of EIs in post-migrant workers. First, this study clarifies the mediating role of attitude toward entrepreneurship in the relationship between proactive personality and entrepreneurial intentions. The results of the analysis show that attitudes toward entrepreneurship change proactive personality into an intention to start a business. Someone who has a proactive personality will have entrepreneurial intentions if $\mathrm{s} /$ he has a positive evaluation toward entrepreneurship and believe that being an entrepreneur is the best career option and will bring benefit. This result also supports previous research by Hu, Wang, Zhang, and Bin (2018) and Rosique-Blasco, Madrid-Guijarro, and Lema (2018). Individuals who have proactivity will be better in identifying opportunities and showing entrepreneurial behavior. Therefore, a proactive personality can be a sign to see someone's tendency to start a business.

There is a significant negative result on the relationship between ESE and EI, which means that an increase in ESE will decrease someone's entrepreneurial intention. This result is contrary to the initial hypothesis and several previous studies showing that ESE has a significant positive effect 
on entrepreneurial intention. Powers (1991) stated that too high self-efficacy will indeed increase optimism to be successful, but this will make a person reduce their motivation and performance toward certain behaviors. Other research studies found that although ESE is thought to have a positive effect on venture creation, very high self-efficacy might increase risk-taking behavior and decrease their effort to achieve something due to overconfidence. Overconfidence and overoptimism have been shown to have mixed effects on entrepreneurial and organizational outcomes (Sun, Vancouver, \& Weinhardt, 2014).

\section{CONCLUSION AND SUGGESTION}

The study shows that the indirect effect of proactive personality and entrepreneurial intention is fully mediated by the attitude toward entrepreneurship, while entrepreneurial self-efficacy is found to have a significant negative effect on entrepreneurial intention of post-migrant workers. Future research might examine whether individuals with high self-efficacy display cognitive biases that lead to negative effects that may occur as a result and the possibility of undiscovered mediators in the relationship between ESE and EI.

\section{REFERENCES}

Asad, A., Ali, H. M \& Islam, U. (2014). The Relationship between entrepreneurship development and unemployment reduction in Pakistan. Global Journal of Management and Business Research, 14(10), 75-79.

Demurger, S., \& Xu, H. (2011). Return migrants: The rise of new entrepreneurs in rural China. World Development, 39 (10), 1847-1861

Hair, J.F., Hult, G.T.M., Ringle, C.M., \& Sardstedt, M. (2017). A Primer on Partial Least Squares Structural Equation Modeling (PLS-SEM). Los Angeles : SAGE

Hu R., Wang L., Zhang W., \& Bin P. (2018). Creativity, proactive personality, and entrepreneurial intention: the role of entrepreneurial alertness. Frontiers in psychology, 9 (951), 1-10.

Khuong, M.N, \& An, N.H. (2016). The factors affecting entrepreneurial intention of the students of Vietnam National University - A mediation analysis of perception toward entrepreneurship. Journal of Economics, Business and Management, 4 (2), 104-111.

Liñán, F., \& Chen, Y.-W. (2009). Development and cross-cultural application of a specific instrument to measure entrepreneurial intentions. Entrepreneurship Theory and Practice, 33(3), 593-617.

Liu, X., Lin, C., Zhao, G. \& Zhao, D. (2019). Research on the effects of entrepreneurial education and entrepreneurial self-efficacy on college students' entrepreneurial intention. Frontiers in psychology, 10 (869), $1-16$.

Miao, C., Qian, S., \& Ma, D. (2017). The relationship between entrepreneurial self-efficacy and firm performance: A meta-analysis of main and moderator effects. Journal of Small Business Management, 55(1), $87-107$.

Prabhu, V. P., McGuire, S. J., Drost, E. A., \& Kwong, K. K. (2012). Proactive personality and entrepreneurial intention. International Journal of Entrepreneurial Behavior \& Research, 18(5), 559-586.

Rosique-Blasco, M., Madrid-Guijarro, A., \& García-Pérez-de-Lema, D. (2017). The effects of personal abilities and self-efficacy on entrepreneurial intentions. International Entrepreneurship and Management Journal, 14(4), 1025-1052.

Seibert, S. E., Kraimer, M. L., \& Crant, J. M. (2001). What do proactive people do? a longitudinal model linking proactive personality and career success. Personnel Psychology, 54(4), 845-874.

Solesvik, M. Z., Westhead, P., Kolvereid, L., \& Matlay, H. (2012). Student intentions to become selfemployed: the Ukrainian context. Journal of Small Business and Enterprise Development, 19(3), 441-460.

Sun, S., Vancouver, J., \& Weinhardt, J. (2014). Goal choices and planning: Distinct expectancy and value effects in two goal processes. Organizational Behavior and Human Decision Processes, 125(2014), 220-233.

Wilson, F., Kickul, J., \& Marlino, D. (2007). Gender, entrepreneurial self-efficacy, and entrepreneurial career intentions: implications for entrepreneurship education. Entrepreneurship Theory and Practice, 31(3), 387-406.

Yueh, H.P., Wu, Y.J., \& Chen, W. (2020). The Psychology and Education of Entrepreneurial Development. Frontiers Media SA: Lausanne 